\title{
, \\ BIM Approach in Construction Safety-A Case Study on Preventing Falls from Height
}

\author{
Fernanda Rodrigues ${ }^{1, *(D)}$, João Santos Baptista ${ }^{2} \mathbb{D}$ and Débora Pinto ${ }^{2}$ \\ 1 RISCO, Civil Engineering Department, University of Aveiro, 3810-193 Aveiro, Portugal \\ 2 Associated Laboratory for Energy, Transports and Aeronautics (PROA/LAETA), Faculty of Engineering, \\ University of Porto, 4200-465 Porto, Portugal; jsbap@fe.up.pt (J.S.B.); deborasuelip@gmail.com (D.P.) \\ * Correspondence: mfrodrigues@ua.pt
}

check for updates

Citation: Rodrigues, F.; Baptista, J.S.; Pinto, D. BIM Approach in Construction Safety-A Case Study on Preventing Falls from Height. Buildings 2022, 12, 73. https:// doi.org/10.3390/buildings12010073 Academic Editors: Junbok Lee and Bjorn Birgisson

Received: 31 October 2021 Accepted: 10 January 2022 Published: 12 January 2022

Publisher's Note: MDPI stays neutral with regard to jurisdictional claims in published maps and institutional affiliations.

Copyright: (C) 2022 by the authors. Licensee MDPI, Basel, Switzerland. This article is an open access article distributed under the terms and conditions of the Creative Commons Attribution (CC BY) license (https:// creativecommons.org/licenses/by/ $4.0 /)$.

\begin{abstract}
The construction industry has one of the highest occupational accident incidence rates among all economic sectors. Currently, building information modelling (BIM) appears to be a valuable tool for analysing occupational safety issues throughout the construction life cycle of projects, helping to avoid hazards and risks and, consequently, increasing safety. This work investigates BIM methodology and the application of related technologies for building safety planning and demonstrates the potential of this technology for the integrated implementation of safety measures during the design phase and construction site management. The first step consisted of a literature review on applying BIM-related technologies for safety in the design and planning phases. Following this, to show the potentialities of construction simulation, a case study based on BIM 4D to prevent falls from height was developed. With BIM 4D, it is possible to follow the construction process over time, giving the construction safety technicians, designers, supervisors and managers the capability to analyse, in each phase, the potential risks and identify which safety measures should be implemented. BIM can effectively integrate safety measures from the design phase to the construction and use phase and enable integrated safety planning within construction planning, leading to reliable safety management throughout the construction process.
\end{abstract}

Keywords: building information modelling; construction safety; planning; safety elements; construction site management; falls from height

\section{Introduction}

Technological developments have occurred in different sectors of activity over the last decades. Nevertheless, in the architecture, engineering and construction (AEC) sector, new technologies in the design, planning and construction phases have not been fully implemented for integrating safety measures in the process [1].

Around the world, only the most competitive and efficient companies are successful in the construction market. Therefore, it is essential to meet quality and safety requirements beyond being productive and obtaining efficient results to have solid growth. For all these purposes, efficient construction management is a crucial element.

According to 2019 Eurostat data, construction was the sector with the highest rate of non-fatal accidents at work among all economic activities, and it had the third-highest rate for fatal accidents between 2011 and 2017. These statistics confirm that this sector is dangerous and lacks the tools for the reliable identification and integration of safety factors. Those figures also reveal that the methodologies currently used are not very effective at reducing the number of occupational accidents in construction [2].

Construction planning, supported by 2D drawings and schedules to describe safety needs at the worksite, has significant constraints when identifying hazards and implementing safety measures. The traditional approach requires engineers and architects to detect the potential hazards and determine the necessary safety procedures based on their 
experience [3]. However, this planning process is complex. Given the dynamic nature of construction projects and the resulting changes in safety requirements, the effect on construction sites drive serious gaps in the risk assessment process [3,4].

Current technologies can effectively support safety management, giving accuracy to the whole process [5]. In the AEC sector, building information modelling (BIM) is considered one of the most promising developments, with users envisaging a full transition to the digitalization of the construction industry [6]. BIM is a collaborative work methodology that can be implemented across all the life cycles of a building, supporting the design, construction and project management phases by using accurate virtual models and the BIM n-dimensions. Within BIM, it is possible to integrate design and construction, to contribute to the higher functional performance of buildings, reducing costs and duration, achieving more sustainable results and higher-quality buildings, increasing safety at the construction sites [3,7], reducing occupational accidents and increasing the safety level and the efficiency of project management [8-10].

A construction project's social, economic and financial impact highlights the particular focus on on-time completion. Effective scheduling is vital for planning and controlling the various processes and time-oriented events along with the project phases. Consequently, effective planning is a crucial success factor in managing and evaluating project performance [11]. Incorrect or inefficient construction planning negatively impacts the construction site's productivity and safety performance [12].

This article presents a case study to assess and depict the potential of 3D and 4D models (integrating the time dimension) in construction safety management.

Thus, the work started with the research question: what contribution can digital tools, such as BIM methodology and its $4 \mathrm{D}$ dimension, give to the integrated planning and management of safety in construction? To answer this question, researchers carried out a literature review. They also developed a case study using three software packages: Autodesk Revit, Microsoft Excel and Autodesk Navisworks. A 4D BIM model was developed using overlapping results from the three software, including its safety measures.

This study's main purpose is to promote BIM in the AEC safety improvement and encourage the earlier integration of safety measures in the design process and all the planning processes, not only in large projects but also in common ones.

This work demonstrates the potential of BIM methodology to implement safety measures from design to construction planning through construction site management, contributing to a lean construction approach.

\section{BIM Technologies for Construction Safety Management}

\subsection{BIM Methodology}

BIM is a holistic concept comprising technologies and processes for managing project data in a digital format throughout a project's life cycles [11]. It is an integrated methodology for digitally exploring projects' physical and functional characteristics before the onsite building execution. Thus, it contributes to a project's faster and more economical delivery while minimizing the environmental impact, occupational safety hazards and the consequent risks. Furthermore, coordinated and consistent information produces innovative design, the better visualization and simulation of real construction conditions [12], the estimation of performance and costs, and the creation of more accurate documentation [13], as well as facilitating resources planning, management and monitoring [12].

The parametric modelling (used in BIM) speeds up the model generation and modification, allowing conflict detection and assessment during the design phase to solve the detected problems in time, before the execution phase [14,15]. BIM visualization and construction simulation also assist in the site planning and resources and material supply planning and budgeting, allowing users to achieve the best construction planning supported by an efficient collaboration among participants throughout the project life cycle $[16,17]$. The interest in using BIM methodology in the AEC sector has grown, especially regarding integrating safety measures throughout the building's life cycle. In addition, 
technological advances in BIM have led to the development of proactive safety solutions to plan and manage worksites [13].

BIM as a collaborative management platform based on 3D BIM models can optimize the construction plan, produce management procedures, and improve the efficiency of construction management measures. BIM can contribute to a more manageable schedule, quality and safety control and improve the degree and efficiency of management information [14]. Nowadays, it is also applied to managing project supervision in the scope of quality, progress, cost and safety [15].

Research studies show that BIM methodology can be successfully applied to occupational safety planning and accident prevention [16-21] and consequently to safety management.

\subsection{BIM-Related Technologies and Safety}

In [22], the capabilities of occupational risk monitoring using different BIM technologies are outlined as follows: BIM design and rules algorithms (e.g., automatic safety checking of construction models and schedules; ontology-based semantic modelling of safety management knowledge; model-based construction work analysis considering process-related hazards); BIM 4D used for occupational risk prevention in the design and planning phases [1,23-25] (e.g., BIM-based site layout and safety planning and integrated safety management with construction management); virtual reality (VR) [26-28] used for virtual hazard identification and visualization and professional training, and design for safety with BIM authoring tools. Prevention through Design (PtD) has been identified as a powerful tool to prevent occupational accidents in the design phase [29,30]. This methodology, using the virtual analysis and simulation available throughout the BIM models, enables the visualization and consequent anticipation of occupational risks in the construction and even in the use phase, allowing users to change the design options and to introduce or link the safety procedures in the model, realizing the goals of designing for safety with BIM [22,31,32].

Thus, BIM's potential for early hazard identification, analysis and prevention is recognised in the design and execution phases [2,33-35]. The BIM 3D models and the BIM 4D construction scheduling simulation allow a detailed, deep and clear understanding of site conditions and all the construction phases by analysing the site's environmental factors and visualising the different project risks [36]. Therefore, it is used for risk assessment, enabling designers and contractors to identify hazards and design and schedule errors, select design alternatives concerning safety in the early design phase and visualise the $4 \mathrm{D}$ model for construction site safety planning [33]. The automation of falling from height hazard detection and its prevention through BIM methodology, using collective protection measures, especially in slabs boundaries, have been studied [4,37]. Aiming to improve project management, 4D BIM was applied so that managers can visualize, assess and prevent project risks throughout the life cycle of a construction project [38]. Construction site simulation can also be integrated with "toolbox" meetings to analyse and discuss activities before starting [16]. It is recognized that BIM enables construction safety management improvement by conjugating and overlaying different tools, including online databases, virtual reality and $4 \mathrm{D}$ schedules [27].

\subsection{Research Summary and Research Objective}

From the literature review, it was possible to conclude that different digital technologies and methodologies within the scope of construction risk prevention are being implemented and developed. Four-dimensional BIM is one of the most used, integrating scheduling, risk assessment and consequent prevention, contributing to integrated construction safety management. This study aims to enhance the advantages of $4 \mathrm{D}$ BIM to improve construction safety management along its life cycle when used in a reinforced concrete structure. It presents a construction management methodology to make occupational risk prevention in general, and falls from height in particular, reliable and integrated with construction planning through 4D BIM, showing that it can be implemented in complex 
projects and common ones. Despite being a research topic addressed by several research works, this paper aims to enhance the importance of integrating safety issues in construction work planning, with particular relevance for temporary structures to protect against falling from height through a case study.

\section{Methodology}

The literature review identified the most commonly used digital technologies in safety in the construction area to understand digital technologies as they are applied to the design and planning phases. The $4 \mathrm{D}$ BIM methodology is one of the most used when the aim is to integrate scheduling and construction management with risk assessment and prevention.

A case study was developed to show the potentialities of digital construction simulation and present, highlight and explain the implemented modelling process phases. For the case study, researchers selected the BIM 4D technology to be used in the planning phase of a radiotherapy centre.

After a deep analysis of the building design (in AutoCAD (2D)), with the Autodesk Revit software architectural and structural 3D models were developed. In parallel, hazard and risk identification were performed, and safety measures to prevent falling from height were pointed out. The correspondent safety equipment was introduced to each model to avoid falls from height throughout the construction phase. With this purpose, and for the construction planning, site routes, traffic directions and site fences were defined, as well as temporary structures, such as guardrails, scaffoldings, platforms and opening coverings [1].

Afterwards, the 4D BIM model was developed using Autodesk Navisworks Manage. This is software for analysis, coordination and compatibility of the different projects, consisting of integration, analysis and communication tools, helping teams coordinate, solve conflicts and plan projects before construction begins, allowing the 3D models to be linked to the respective schedule, thus obtaining a 4D simulation. Microsoft Excel incorporated the time component (fourth dimension) to construction planning. With this integration, it was possible to simulate the building evolution over time. Safety measures to be implemented have been incorporated in this fourth dimension as links to safety instructions (safety files). Figure 1 depicts the methodology applied during this work.

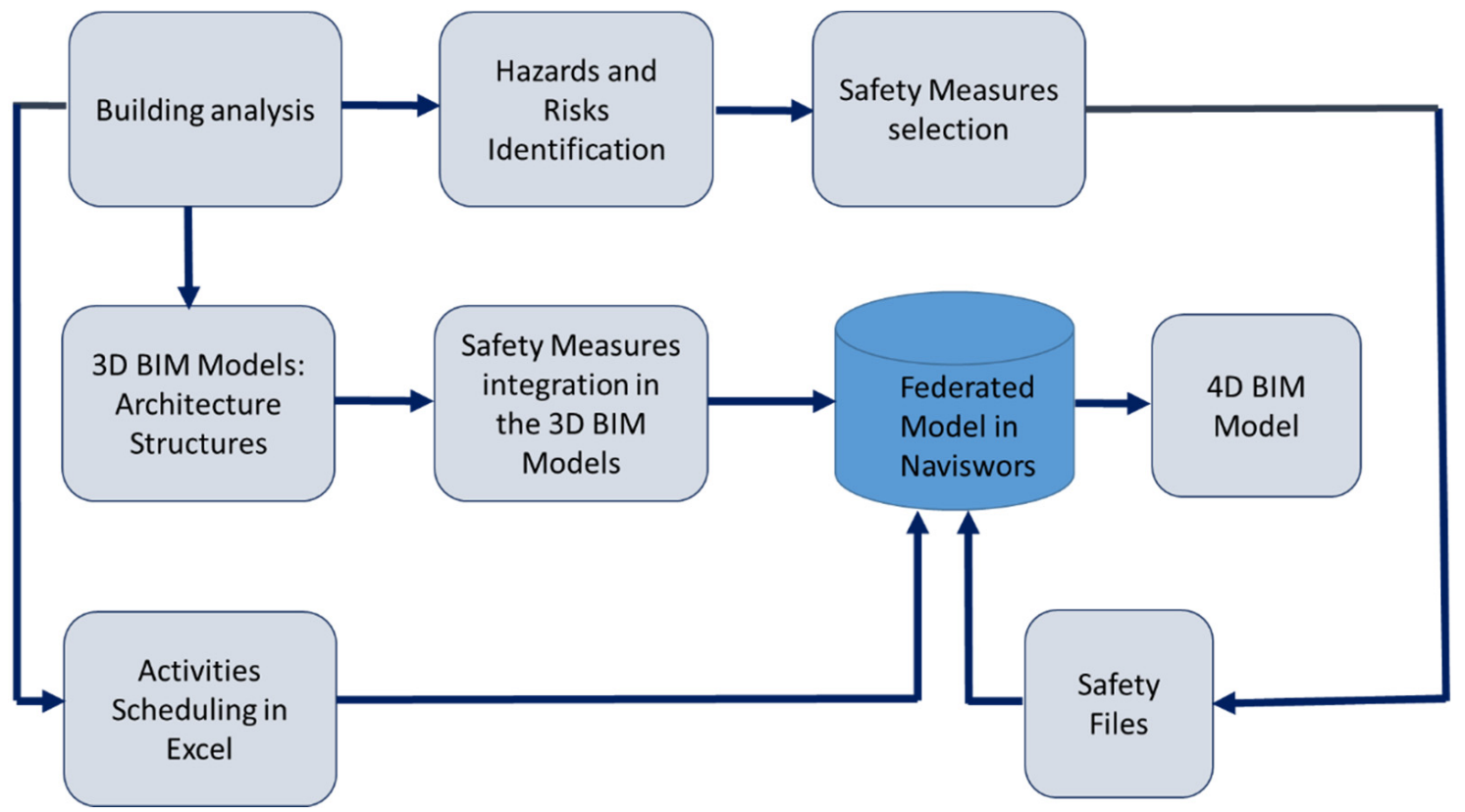

Figure 1. Methodology diagram. 


\section{Case Study}

The case study in this article is a two-storey building located in Madeira (a Portuguese island in the Atlantic Ocean). The building design was developed in AutoCAD (2D). The building consists of two floors: a basement and a ground floor. The basement is wholly buried with a structure composed of reinforced concrete walls around the entire perimeter to support the soil and prevent radiation propagation to the surrounding areas. The radiotherapy centre's design was analysed through AutoCAD (2D) for architecture and structural design. In addition, documents containing the operating instructions and the safety measures (safety files/instructions) for the construction phase were prepared to be linked with the BIM $4 \mathrm{D}$ model. These safety files focus on preventing risks in different activities, such as concrete pouring in structural elements, and the assembly and disassembly of formwork elements, including the assembly and disassembly of scaffolding and guardrails. The next step was to develop the architectural and structural 3D models in Revit. They allowed the application of safety measures, emphasising the use of temporary structures. External online libraries (Revit City.com, Bimstore.co, BIMobject and BIM\&CO) were used to import objects, such as scaffolding, platforms and construction fences.

Despite significant research on the use of such objects, few were available in these libraries. The authors developed some families, including guardrails with a clamping system, guardrails with a spike system and hole covers (see figures of these families in Section 4.4).

The safety elements incorporated into the structural model included two families of guardrails, hole covers, routes / traffic directions and the site fence (Figure 2). In addition, the scaffolding and the working platform at height were integrated with the architectural model (Figure 3). This distinction between the placement of the safety elements was necessary because of their separated and sequential use throughout the construction phases. Finally, the two 3D models were overlapped in Navisworks, generating a federated model (Figure 4).

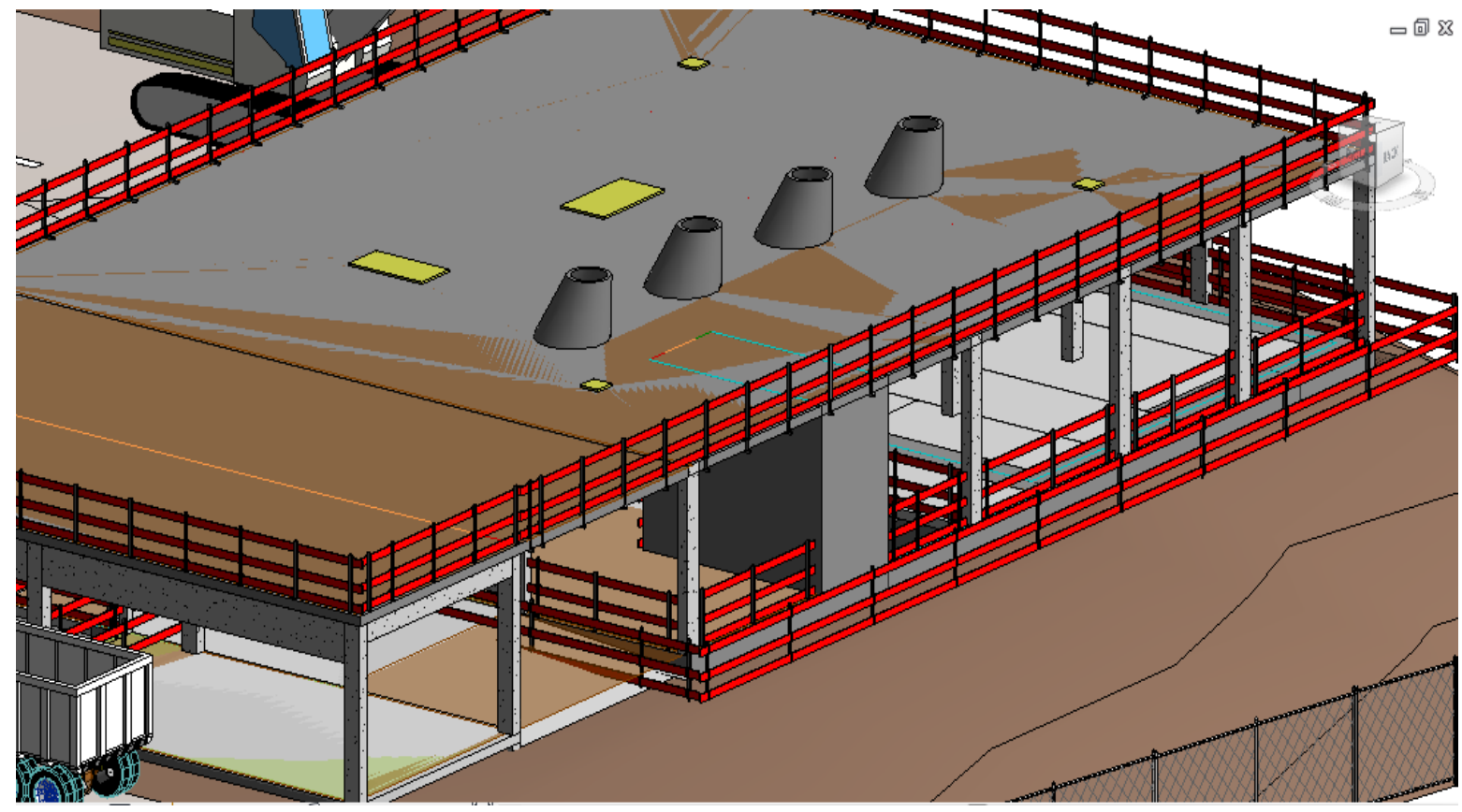

Figure 2. The structural 3D model with safety elements. 


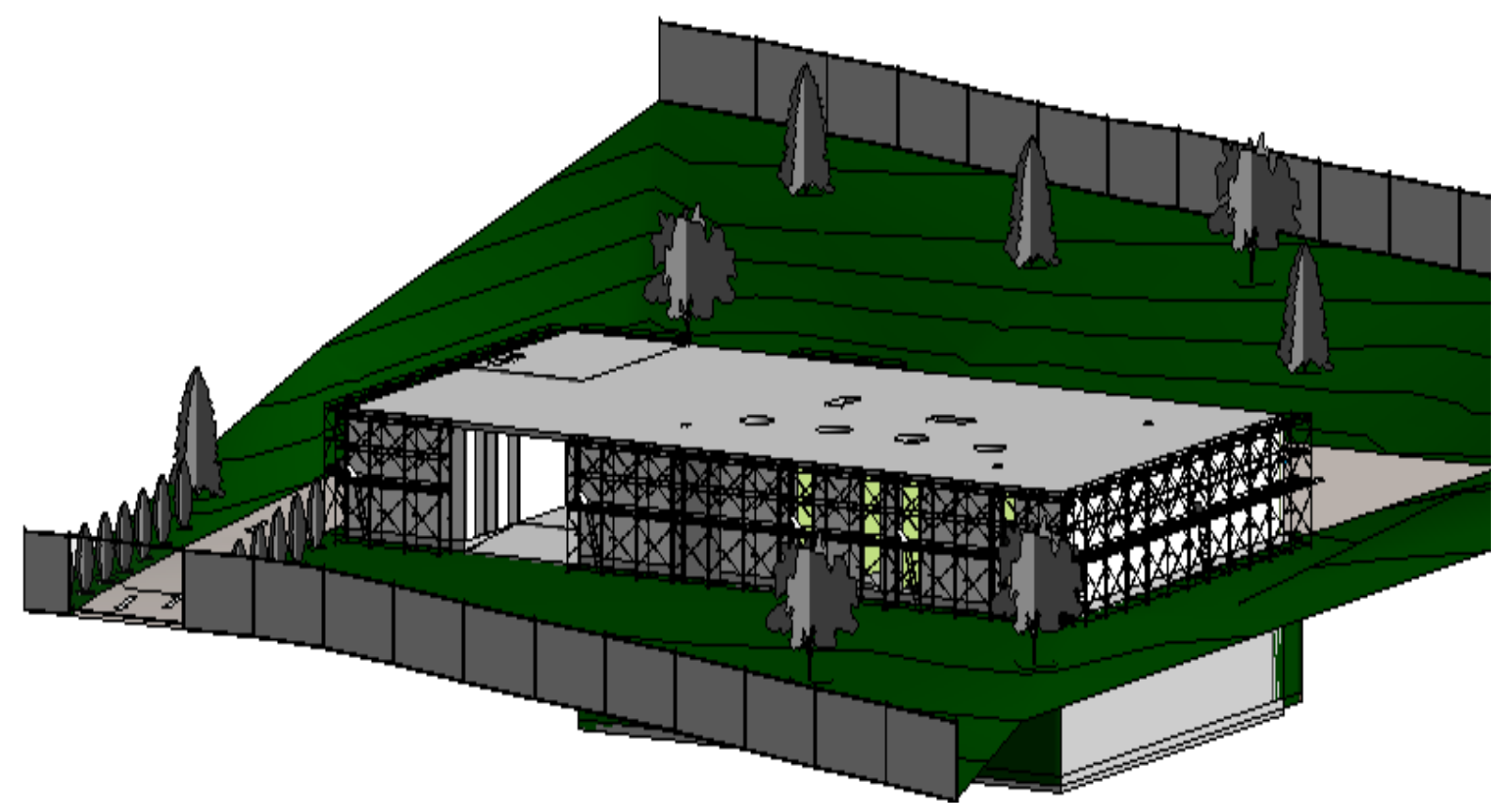

Figure 3. Architecture 3D model with safety equipment.

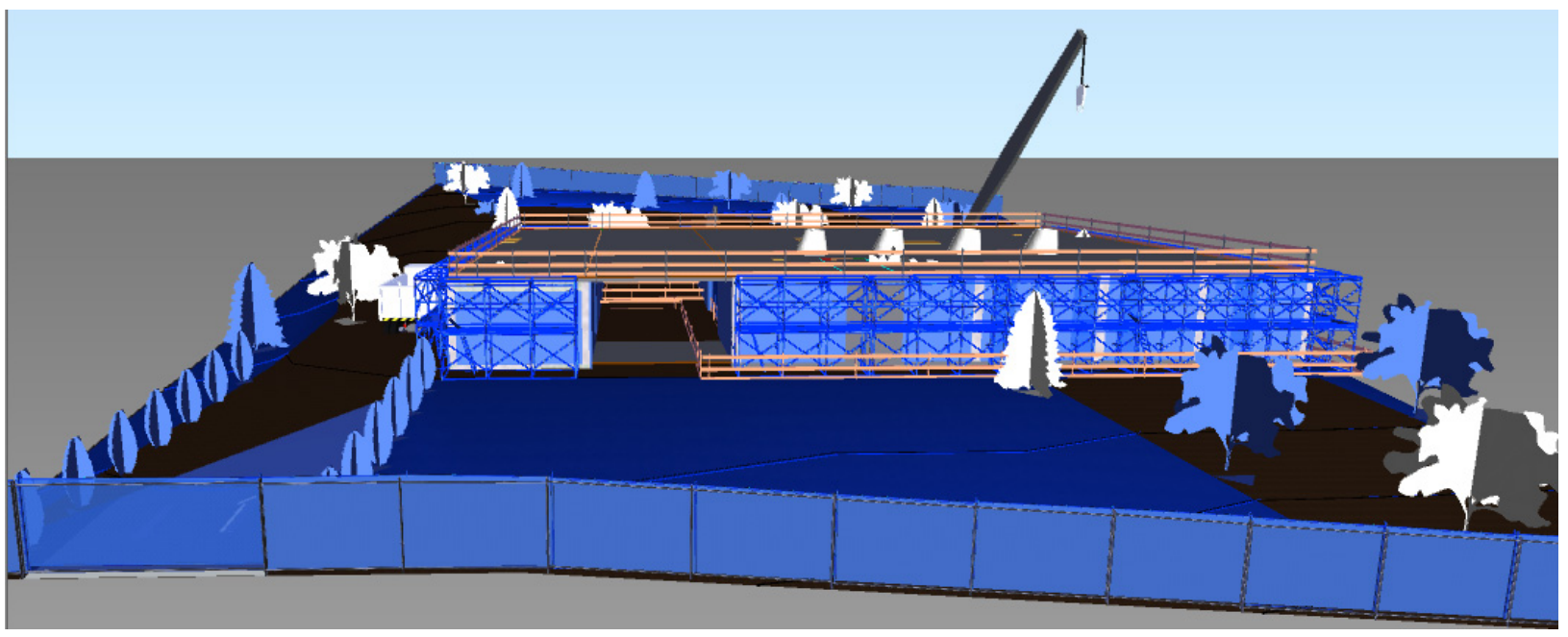

Figure 4. Federate model using Navisworks software.

The 4D model was created by adding the time component to the Navisworks federated model. The time component was generated from the activity schedule developed in Microsoft Excel. This schedule considered the main construction activities and the temporary tasks, which correspond to the use of safety systems and the expected beginning and end for each task to protect against falling from height. To achieve a realistic definition of the work sequence (Table 1), there should be a thorough understanding of the activities behind the entire schedule. Throughout the planning phase, designers must give critical thought to the timing of the placement and the removal of temporary structures and safety elements since they remain for different periods at the worksite. 
Table 1. Assembly and disassembly of temporary structures according to the work sequence.

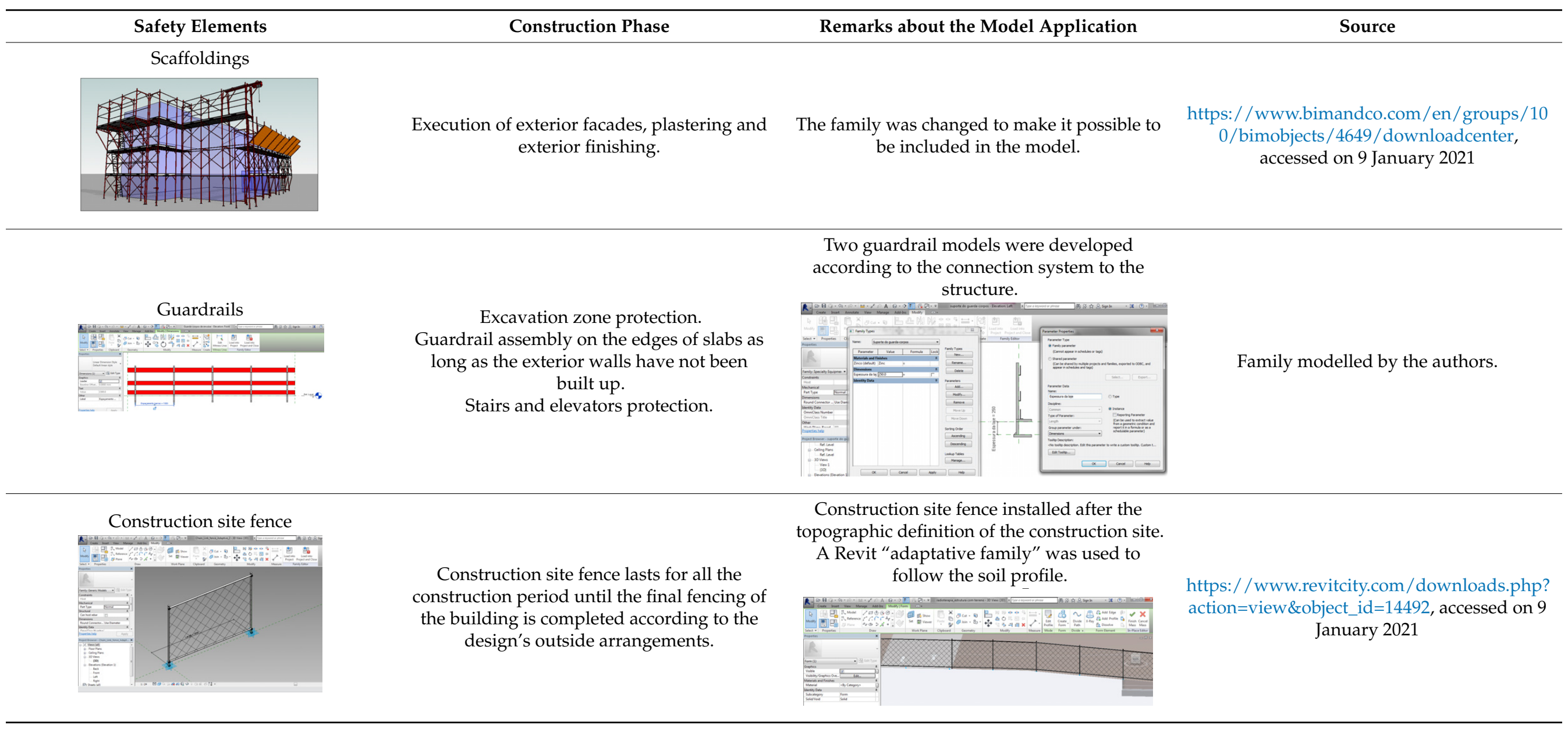


Table 1. Cont.

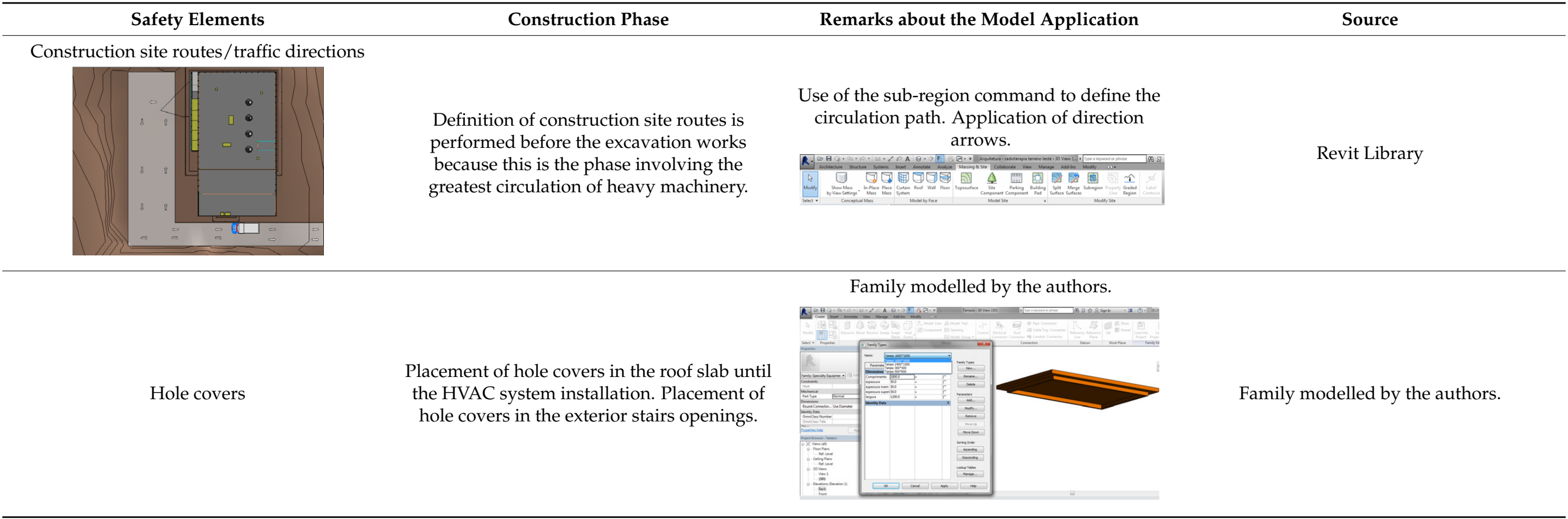


Safety files were also developed. Tools, such as comments and links to these safety files, were inserted within the 4D model to reinforce safety, add information on temporary tasks and point out the need to consult safety files/instructions about the assembly/disassembly of scaffolding and guardrails (Figure 5). These documents provide detailed descriptions of the assembly/disassembly of scaffolding and guardrails, hazards, risks and preventive measures.
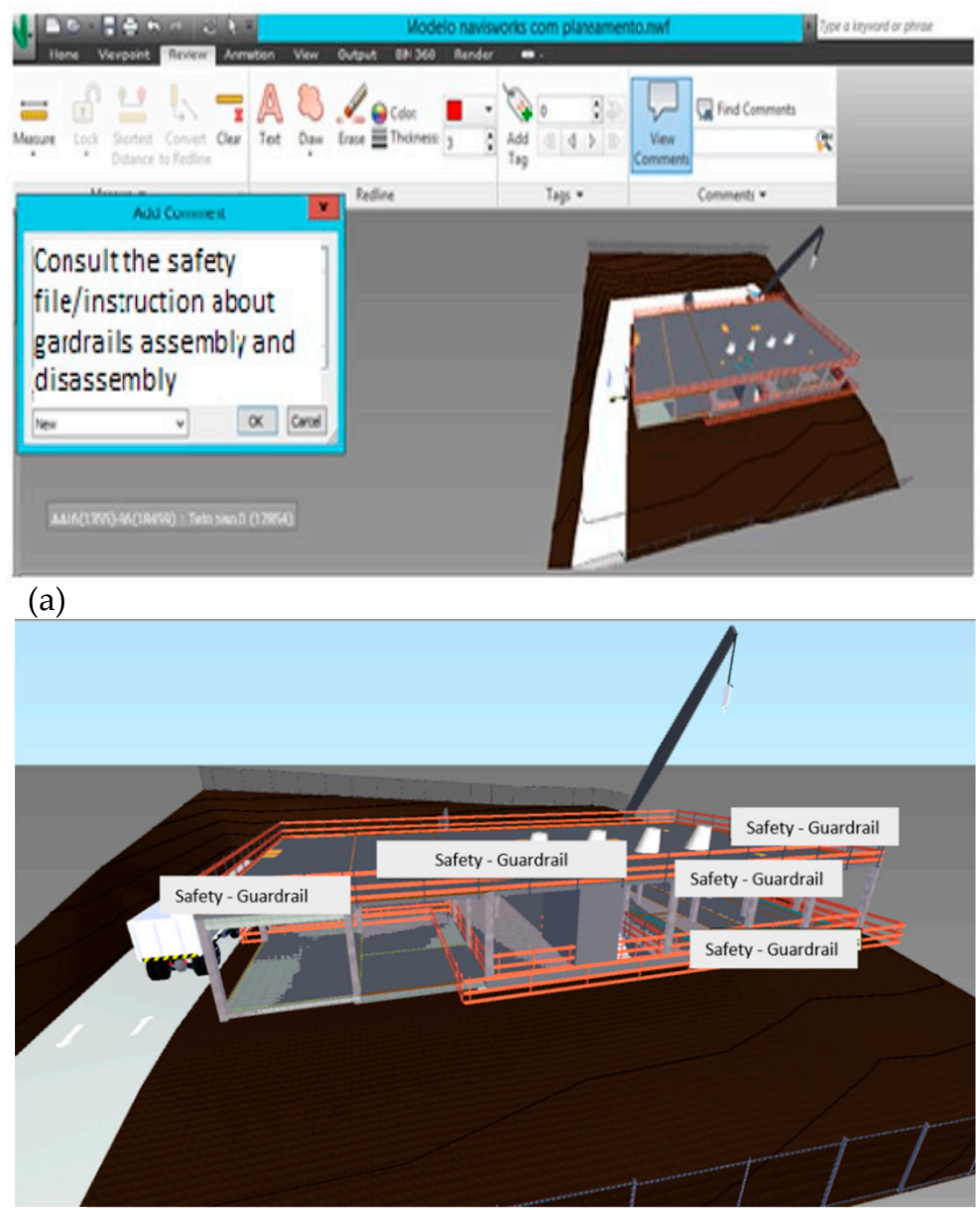

(b)

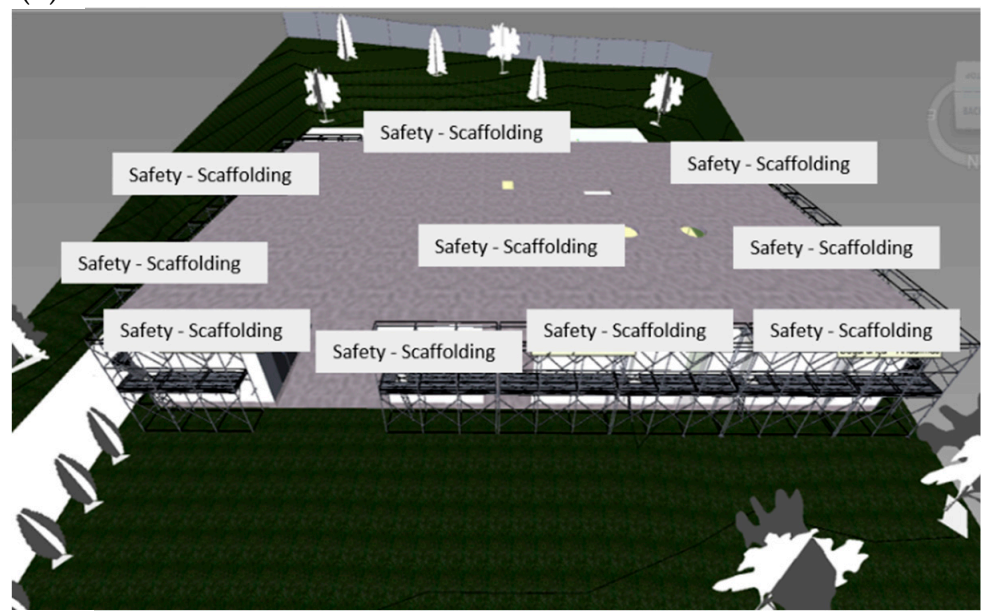

(c)

Figure 5. Links to comments (a) and safety files about guardrail (b) and scaffolding (c) assembly/disassembly. 
Associating tasks with the planned schedule created a 4D simulation to follow the work requirements regarding safety during the entire construction project. Applying the Navisworks simulation tool to the $4 \mathrm{D}$ model made it possible to track the worksite development over time visually and to determine, at each moment, necessary safety interventions and management needs. Navisworks simulation produced a colour-coded graphic in which each colour is associated with a type of task. Each task type has the following graphic meanings:

- Construction: when the task starts, the elements referring to the task are displayed in green and, upon completion, their colour turns to the colour of the Revit model.

- Demolish: at the task beginning, the elements to demolish are denoted with the colour red and disappear at the end.

- Temporary: the elements are coloured yellow for temporary structures and disappear on the defined date.

Figure 6 shows the simulation of some of the construction phases with a colour-coded explanation:

(a) Construction site preparation phase. The soil is coloured red because of earth movement.

(b) Excavation and fencing of the construction site. The topography appears in yellow because it changed during the construction process. The excavation zone is coloured red because of the soil extraction. The fence is a temporary structure, so it is coloured yellow.

(c) Guardrail placement in the excavation zone. Because these elements are temporary structures, they are a yellow colour.

(d) Structure of the -1 floor. The completed concrete structure, in that phase, has the final colour of the project (colour of the Revit model).

(e) Waterproofing of the -1 floor and guardrails on floor 0 . These temporary elements are represented in yellow.

(f) Placement of guardrails on the flat roof. These temporary elements are represented in yellow.

(g) Placement of scaffolding and execution of exterior walls. The scaffolding is coloured yellow, and the exterior walls during construction are green.

(h) Completed building. All of the work has concluded, and the final elements correspond to the colours of the graphic model in Revit. 


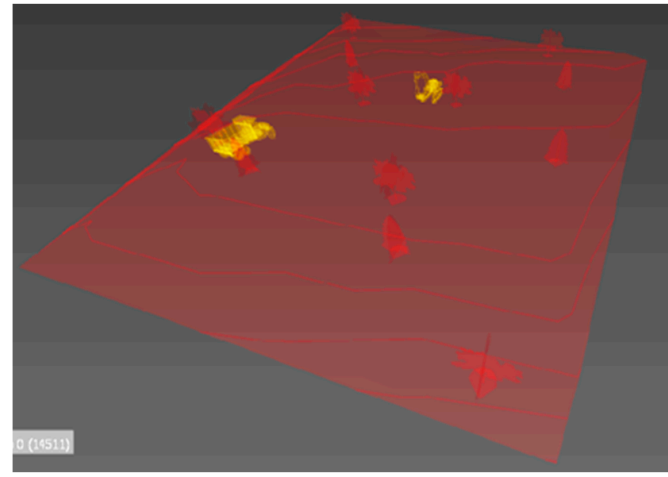

(a) Construction site preparation

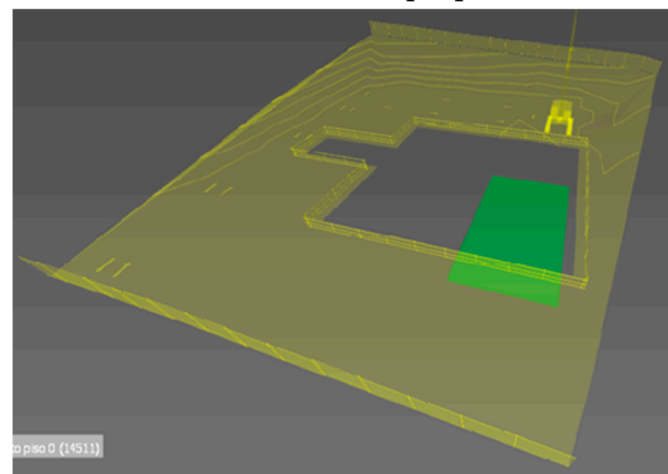

(c) Guardrail placement in the excavation zone

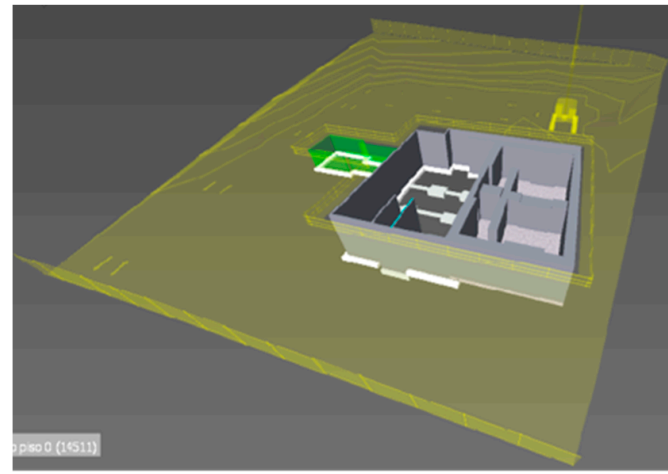

(e) The -1 floor structure and guardrail placement on the 0-floor level

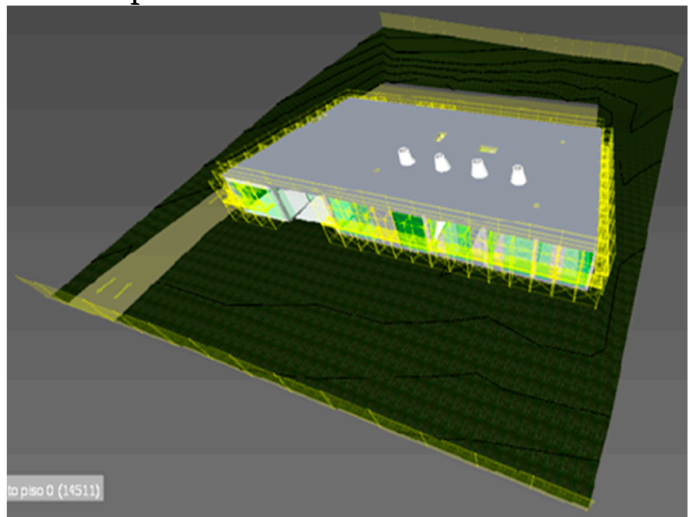

(g) Scaffolding and exterior walls execution

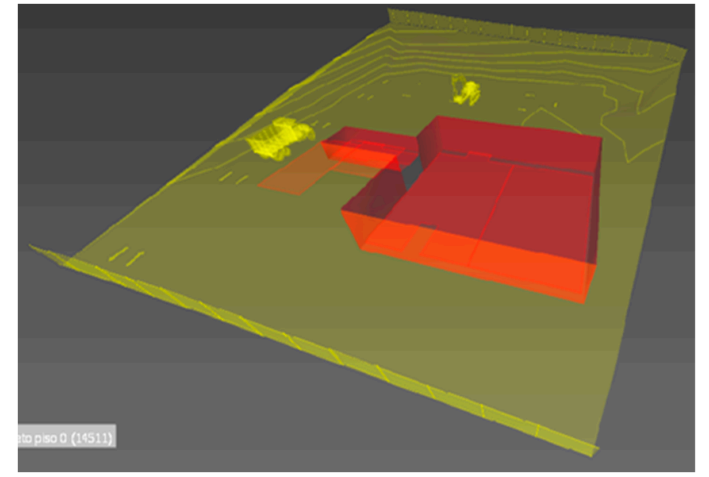

(b) Excavation and fencing of the construction site

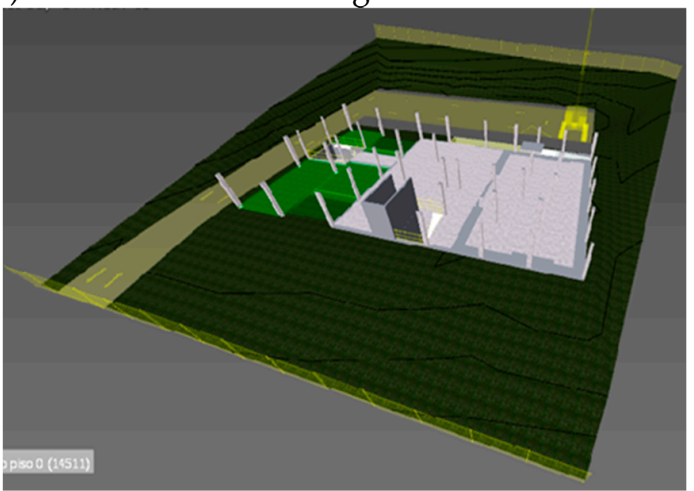

(d) Structure of the -1 floor

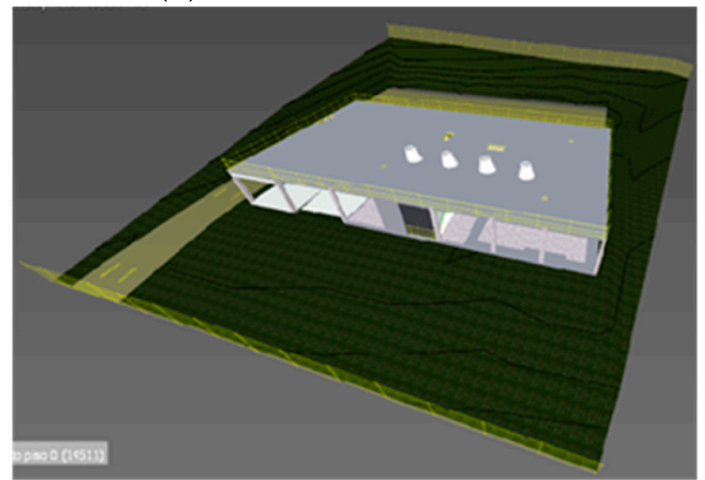

(f) Placement of guardrails on the flat roof

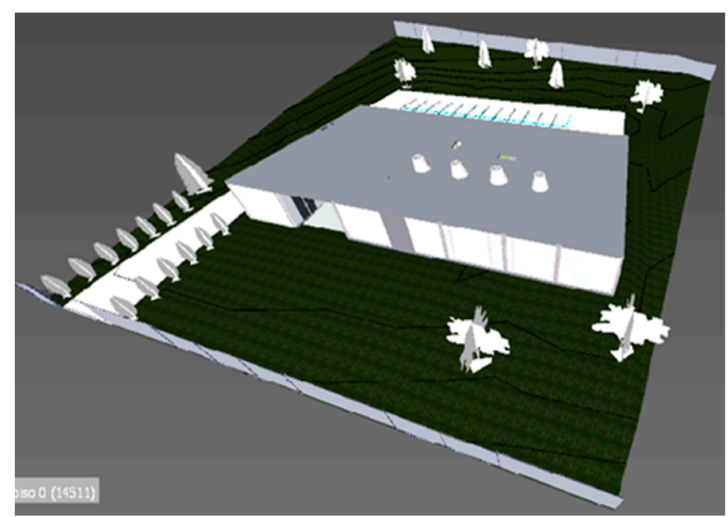

(h) Completed building

Figure 6. Case study 4D simulation. 


\section{Results and Findings}

\subsection{Technologies}

The literature review verified that safety management is performed throughout three phases of a building's life cycle: design/planning, construction and maintenance. The framework proposed by [39] prescribes a long-term risk management strategy and a process that allows stakeholders to work collaboratively to manage risks throughout the project life cycle. The risk mitigation model developed by [39] demonstrates that the risk mitigation process should be implemented as early as possible, especially during the design or planning phase, and that most risks should be "designed out" during the design and planning phases, leaving only the management of residual risks in the construction and subsequent phases.

Planning for safety in the early stages of a project contributes to a considerable decrease in risks. The literature review revealed several digital tools developed to be used in the design and construction phases for more accurate occupational risk prevention.

\subsection{Design Phase}

In the design phase, the prevention through design (PtD) methodology addresses occupational safety to prevent or minimise the hazards and risks associated with all phases of a building's life cycle, whether in construction, manufacture, use or maintenance $[22,40]$. The fundamental effort in promoting PtD is to improve communication and coordination among stakeholders. This change is expected to fill design and construction phase gaps. However, this change is not sufficient to minimise hazards and risks. Another approach involves conducting a thorough risk assessment of each design component. This assessment usually involves using various tools, such as safety manuals, checklists and software, to help designers access construction safety knowledge. Technological advances allow designers to automatically check building plans against building codes [40], and researchers are currently performing semantic research enrichment of building information models to support automated code compliance checking [41].

Ideally, a PtD software tool should help designers during the design phase, informing them of alternative design options and the safety consequences of various solutions. Furthermore, the tool should be capable of avoiding risks, detecting and correcting for safety by default. By performing these functions, a PtD tool would provide appropriate safety knowledge at the right time, improving safety in the design phase [31,37,42].

However, most risk identification and mitigation of potential construction hazards rely on the designer's competence. If designers do not have the knowledge or competence to deeply identify hazards and understand the construction tasks, sequence and coordination, they cannot eliminate/minimize hazards and improve occupational safety [43].

Thus, the 3D BIM models developed with an integrated goal of achieving higher safety performance depict a high potential for occupational risk prevention and safety management purposes.

\subsection{Planning Phase}

As BIM provides an accurate design model and details on the resources required, it provides the basis for the improved planning and scheduling of subcontractors, helping to ensure that people, equipment and materials arrive at the proper time to reduce the waste of time and to facilitate better collaboration at the worksite [7,44]. This control permits designers to implement lean construction techniques [45], reducing failures in general and occupational accidents in particular.

As one of the phases that most contributes to risk reduction, construction planning was highlighted, where designers and stakeholders have made an essential investment in improving safety conditions [39]. However, despite the availability of technologies that can assist in this process, designers still plan most construction projects manually [46], especially the medium and small ones. 
The technologies of BIM 4D, among others, are helpful for the planning phase. This technology adds construction planning information to a 3D model, clearly visualising construction sequences. The application of BIM $4 \mathrm{D}$ also improves the safety and health management of the construction process [46,47]. For safety applications, BIM 4D consists of establishing a comprehensive $4 \mathrm{D}$ model that combines all project data on construction objects, processes, activities and sequences and helps when conducting a risk analysis based on the developed model [39], allowing occupational risk assessment and prevention [40]. In the literature review, different case studies were developed in which 3D and 4D BIM are used for different purposes.

This case study paid special attention to scheduling temporary safety equipment for risk prevention due to falling from height and its correct sequence of assembly and disassembly from the excavation until the final works (Figure 7). This sequence and the failures frequently observed in these processes are often the cause of accidents in the construction sites.

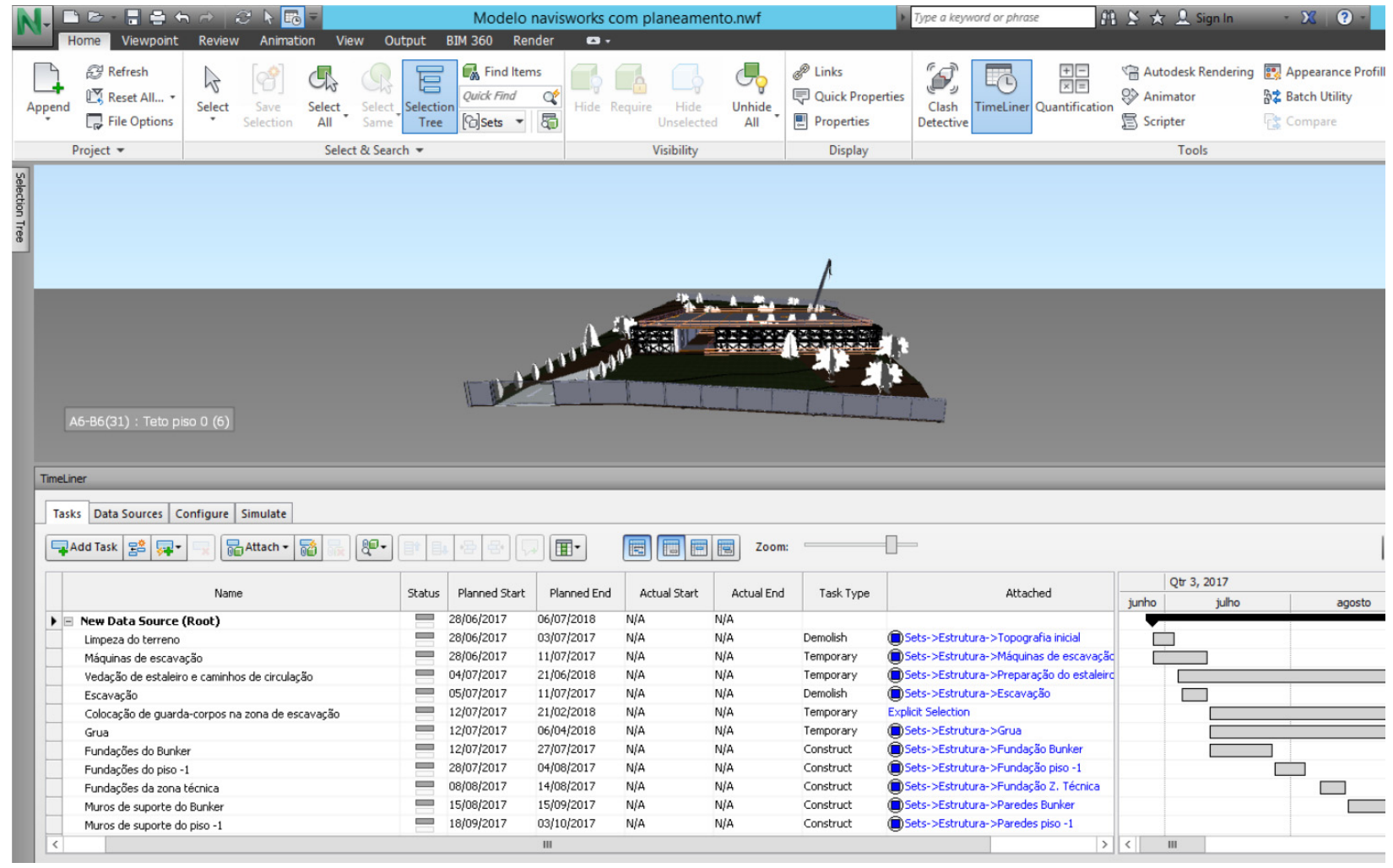

Figure 7. Construction building planning.

\subsection{Modelling}

Guardrails with a clamping system, guardrails with a spike system and hole covers were modelled, as was the sharing of parameter information for further quantification. It was possible to automatically extract the maps of quantities needed for safety equipment management from these families. Tables 2 and 3 depict some information about these quantity take-offs. Automatic quantity calculation is a standard procedure when working with BIM methodology but, it is an important part of safety and construction management as a whole. 
Table 2. Maps of quantities—guardrails hole covers (excerpt).

\begin{tabular}{|c|c|c|c|c|c|}
\hline Type & Figure & Length (mm) & Bar Spacing (mm) & N. ${ }^{\circ}$ of Bars & $\begin{array}{c}\text { Slab } \\
\text { Thickness (mm) }\end{array}$ \\
\hline $\begin{array}{l}\text { Guardrails with } \\
\text { clamping system }\end{array}$ & & 4197 & 1500 & 3 & 200 \\
\hline $\begin{array}{l}\text { Guardrails with } \\
\text { spike system }\end{array}$ & & 4260 & 2000 & 2 & - \\
\hline
\end{tabular}

Table 3. Maps of quantities-hole covers (excerpt).

\begin{tabular}{|c|c|c|c|c|c|c|c|}
\hline Level & Type & Figure & With (mm) & $\begin{array}{c}\text { Length } \\
\text { (mm) }\end{array}$ & Tab (mm) & $\begin{array}{c}\text { Lower } \\
\text { Thickness } \\
(\mathrm{mm})\end{array}$ & $\begin{array}{c}\text { Upper } \\
\text { Thickness } \\
(\mathrm{mm})\end{array}$ \\
\hline Floor 0 & $\begin{array}{c}\text { Cover } \\
2400 \times 1500\end{array}$ & & 1700 & 2600 & 100 & 50 & 50 \\
\hline \multirow{3}{*}{ Ceiling } & $\begin{array}{c}\text { Cover } \\
300 \times 300\end{array}$ & & 500 & 500 & 100 & 50 & 50 \\
\hline & $\begin{array}{c}\text { Cover } \\
1800 \times 800\end{array}$ & & 1000 & 2000 & 100 & 50 & 50 \\
\hline & $\begin{array}{c}\text { Cover } \\
2000 \times 989\end{array}$ & & 1189 & 2200 & 100 & 50 & 50 \\
\hline
\end{tabular}

It was not possible to extract data from the remaining elements, such as scaffolding and fences because their families were not designed to share information at that level. Therefore, when working with families of elements that do not exist in the Revit library and when using external libraries, these families may not provide the necessary information to effectively design for the project's needs. Thus, designers must be aware of the parameterization used in modelling new families and the use of families designed by other authors (with shared or non-shared parameters) according to the model's objective.

\section{Discussion}

With the ability to incorporate comments and links in the BIM 4D model and the capacity to quantify safety elements, construction safety technicians, designers, supervisors and managers have at their disposal a complete set of safety tools in a global work methodology integrated into a single model. In advance, it is possible to identify the safety measures that need to be implemented during the entire construction period by following the simulation and consulting the safety documents integrated into the model simultaneously. In the present case study, it was possible to analyse the evolution of the project's execution, the need for protection measures against falls from height and the correct sequence of the assembly and disassembly of temporary structures for the duration of the whole construction, and quantify the needs for guardrails and hole covers. This approach, integrated with construction management in a comprehensive overview, leads to more efficient and safer construction management.

The model and its virtual simulation are also excellent tools to provide professional training. It is possible to have, simultaneously, an overview and a detailed view of the whole construction process and the safety measures that should be applied at each stage. In addition, to simplify the designers' work, this approach can be used in the daily routine in the construction site, allowing the reinforcement of the safety culture.

Some Revit families regarding safety at work are missing from the BIM libraries, so it was necessary to model some safety objects (guardrails and hole covers). This omis- 
sion demonstrates how safety remains a secondary concern, even in digital technologies, compared with other project specialities.

More detailed work planning and more information being available for 4D BIM model simulation would bring greater control over the worksite. Another feature of the BIM methodology is that changes made directly to the 3D model are automatically updated to the 4D model. In this way, the loss of information is avoided. This automatic updating effectively improves communication among stakeholders throughout the construction process, avoiding delays in the timely detection of project changes and/or in planned tasks, thereby avoiding errors and improving construction management quality.

Using this methodology makes sure that safety management is integrated with the whole of the project management, creating a more efficient process and avoiding opportunities for unforeseen events. Its use will also reduce workplace accidents and implement safety procedures more efficiently.

This case study confirms the complexity of preparing the models and the advantages of BIM methodology in preventing occupational risks in any construction project.

\section{Conclusions}

The AEC sector has been implementing advanced technologies to achieve higher quality, productivity and safety levels. However, using these tools requires an excellent understanding of their capabilities. In addition, the designers and other stakeholders also often lack training in identifying hazards and implementing safety measures.

This paper demonstrates the importance of a collaborative and integrated methodology for designing, planning, construction and the use phases, aiming at effective occupational risk prevention and safety planning. It also highlights and shows that using new methodologies, such as BIM, can optimize construction processes, making it possible to plan effective safety measures across space and time through 4D BIM simulations, with real-time control and work planning knowledge. Furthermore, BIM methodology fills gaps in the traditional methods (2D) by gathering diverse information in one model, updating changes to the model automatically and providing rapid, digital communication among all the stakeholders of the construction project and facilitating the planning of the production processes, considering simultaneously the occupational risk assessment and the corresponding safety measures.

Compared with the widely used 2D approach, 4D models enable faster and easier visualisation and perception of work developments and safety needs, allowing quicker and more reliable decision making. The literature review highlights that the 4D model permits the integrated and reliable identification and prevention of occupational risks.

Given that construction is a continuous process, there should be no gaps between the different phases regarding safety. With the growing complexity of construction projects and the requirement for their fast completion, the occupational risks related to their implementation in the field are also increasing. Accidents have high economic and social costs that must be avoided. Thus, safety procedures require investments that must be accounted for in the construction process budget. At all stages, the coordination of safety procedures requires adopting solutions for planning, design and execution, and good communication between stakeholders throughout the process. The construction management methodology presented led to making occupational risk prevention reliable and integrated with the construction planning through 4D modelling, not only in large and complex projects but also in common ones. Therefore, this work is interesting to other researchers and practitioners who need diversified information sources on how to overcome specific problems in implementing safety in the different construction phases using current digital technologies.

The following research will develop a 4D integrated approach, including construction activities, safety, works planning, the automatic production of procedures, using the last planner system methodology. 
Author Contributions: Author Contributions: Conceptualization and methodology F.R., D.P.; investigation F.R., D.P.; writing-original draft preparation F.R., D.P.; writing-review and editing; supervision, F.R., J.S.B. All authors have read and agreed to the published version of the manuscript.

Funding: This research received no external funding.

Data Availability Statement: All the important data are in the article.

Conflicts of Interest: The authors declare no conflict of interest.

\section{References}

1. Pinto, D.; Rodrigues, F.; Baptista, J.S. The contribution of digital technologies to construction safety. In Proceedings of the Occupational Safety and Hygiene VI, Guimarães, Portugal, 26-27 March 2018; CRC Press: Boca Raton, FL, USA, 2018 ; pp. 115-119.

2. Zhang, S.; Teizer, J.; Lee, J.-K.; Eastman, C.M.; Venugopal, M. Building Information Modeling (BIM) and Safety: Automatic Safety Checking of Construction Models and Schedules. Autom. Constr. 2013, 29, 183-195. [CrossRef]

3. Guo, H.; Yu, Y.; Skitmore, M. Visualization technology-based construction safety management: A review. Autom. Constr. 2017, 73, 135-144. [CrossRef]

4. Zhang, S.; Sulankivi, K.; Kiviniemi, M.; Romo, I.; Eastman, C.M.; Teizer, J. BIM-based fall hazard identification and prevention in construction safety planning. Saf. Sci. 2015, 72, 31-45. [CrossRef]

5. Zhou, Z.; Irizarry, J.; Li, Q. Applying advanced technology to improve safety management in the construction industry: A literature review. Constr. Manag. Econ. 2013, 31, 606-622. [CrossRef]

6. Parn, E.; Edwards, D. Conceptualising the FinDD API plug-in: A study of BIM-FM integration. Autom. Constr. 2017, 80, 11-21. [CrossRef]

7. Sacks, R.; Eastman, C.; Lee, G.; Teicholz, P. BIM Handbook: A Guide to Building Information Modeling for Owners, Designers, Engineers, Contractors and Facility Managers; John Wiley and Sons: Hoboken, NJ, USA, 2018.

8. Al-Ashmori, Y.Y.; Othman, I.; Rahmawati, Y.; Amran, Y.H.M.; Sabah, S.H.A.; Rafindadi, A.D.; Mikić, M. BIM benefits and its influence on the BIM implementation in Malaysia. Ain Shams Eng. J. 2020, 11, 1013-1019. [CrossRef]

9. Jiang, M.; Cheng, Y.; Lei, T.; Liu, Z. “Intelligent Construction, Digital Modeling of the Future" Internet + BIM Service EPC Project-Take the Exhibition Center of National Cybersecurity Center for Education and Innovation Project as an Example. IOP Conf. Ser. Earth Environ. Sci. 2021, 719, 22043. [CrossRef]

10. Li, Z. The Application of BIM Technology in the whole Life Cycle of Construction Project. IOP Conf. Ser. Earth Environ. Sci. 2020, 510, 62004. [CrossRef]

11. Getuli, V.; Capone, P.; Bruttini, A.; Isaac, S. BIM-based immersive Virtual Reality for construction workspace planning: A safety-oriented approach. Autom. Constr. 2020, 114, 103160. [CrossRef]

12. Dashti, M.S.; RezaZadeh, M.; Khanzadi, M.; Taghaddos, H. Integrated BIM-based simulation for automated time-space conflict management in construction projects. Autom. Constr. 2021, 132, 103957. [CrossRef]

13. Enshassi, A.; Ayyash, A.; Choudhry, R.M. BIM for construction safety improvement in Gaza strip: Awareness, applications and barriers. Int. J. Constr. Manag. 2016, 16, 249-265. [CrossRef]

14. Miao, D. Application of BIM Technology in the Informatization of Construction Management. In Proceedings of the International Conference on Cognitive based Information Processing and Applications (CIPA 2021), Beijing, China, 28 August-1 September 2021; Springer: Singapore, 2022; pp. 613-621.

15. Yan, H.; Wang, L.; Jiang, X. Dynamic Control of Integrated Project Management System based on Engineering Projects. Comput. Des. Appl. 2021, 19 (Suppl. S4), 90-101. [CrossRef]

16. Ganah, A.A.; John, G.A. BIM and project planning integration for onsite safety induction. J. Eng. Des. Technol. 2017, 15, 341-354. [CrossRef]

17. Kim, K.; Cho, Y.; Zhang, S. Integrating work sequences and temporary structures into safety planning: Automated scaffoldingrelated safety hazard identification and prevention in BIM. Autom. Constr. 2016, 70, 128-142. [CrossRef]

18. Takim, R.; Zulkifli, M.H.; Nawawi, A.H. Integration of Automated Safety Rule Checking (ASRC) System for Safety Planning BIM-Based Projects in Malaysia. Procedia-Soc. Behav. Sci. 2016, 222, 103-110. [CrossRef]

19. Zadeh, P.A.; Wang, G.; Cavka, H.B.; Staub-French, S.; Pottinger, R. Information Quality Assessment for Facility Management. Adv. Eng. Inform. 2017, 33, 181-205. [CrossRef]

20. Fadeyi, M.O. The role of building information modeling (BIM) in delivering the sustainable building value. Int. J. Sustain. Built Environ. 2017, 6, 711-722. [CrossRef]

21. Getuli, V.; Ventura, S.M.; Capone, P.; Ciribini, A.L. BIM-based Code Checking for Construction Health and Safety. Procedia Eng. 2017, 196, 454-461. [CrossRef]

22. Wetzel, E.M.; Thabet, W.Y. The use of a BIM-based framework to support safe facility management processes. Autom. Constr. 2015, 60, 12-24. [CrossRef]

23. Choi, B.; Lee, H.-S.; Park, M.; Cho, Y.K.; Kim, H. Framework for Work-Space Planning Using Four-Dimensional BIM in Construction Projects. J. Constr. Eng. Manag. 2014, 140, 4014041. [CrossRef]

24. Sawyer, T. Construction managers embrace 4D BIM for safety. ENR 2014, 272, 22. 
25. Chen, L.; Luo, H. A BIM-based construction quality management model and its applications. Autom. Constr. 2014, 46, 64-73. [CrossRef]

26. Cheng, T.; Teizer, J. Real-time resource location data collection and visualization technology for construction safety and activity monitoring applications. Autom. Constr. 2013, 34, 3-15. [CrossRef]

27. Zhou, W.; Whyte, J.; Sacks, R. Construction safety and digital design: A review. Autom. Constr. 2012, 22, 102-111. [CrossRef]

28. Park, C.-S.; Kim, H.-J. A framework for construction safety management and visualization system. Autom. Constr. 2013, 33, 95-103. [CrossRef]

29. Gambatese, J.A.; Behm, M.; Rajendran, S. Design's role in construction accident causality and prevention: Perspectives from an expert panel. Saf. Sci. 2008, 46, 675-691. [CrossRef]

30. Rodrigues, F.; Coutinho, A.; Cardoso, C. Correlation of causal factors that influence construction safety performance: A model. Work 2015, 51, 721-730. [CrossRef]

31. Qi, J.; Issa, R.R.A.; Olbina, S.; Hinze, J. Use of Building Information Modeling in Design to Prevent Construction Worker Falls. J. Comput. Civ. Eng. 2014, 28, A4014008. [CrossRef]

32. Zhang, S.; Boukamp, F.; Teizer, J. Ontology-based semantic modeling of construction safety knowledge: Towards automated safety planning for job hazard analysis (JHA). Autom. Constr. 2015, 52, 29-41. [CrossRef]

33. Jin, Z.; Gambatese, J.; Liu, D.; Dharmapalan, V. Using 4D BIM to assess construction risks during the design phase. Eng. Constr. Arch. Manag. 2019, 26, 2637-2654. [CrossRef]

34. Malekitabar, H.; Ardeshir, A.; Sebt, M.H.; Stouffs, R. Construction safety risk drivers: A BIM approach. Saf. Sci. 2016, 82, 445-455. [CrossRef]

35. Hongling, G.; Yantao, Y.; Weisheng, Z.; Yan, L. BIM and Safety Rules Based Automated Identification of Unsafe Design Factors in Construction. Procedia Eng. 2016, 164, 467-472. [CrossRef]

36. Hardin, B.; McCool, D. BIM and Construction Management: Proven Tools, Methods, and Workflows; Wiley: Indianopolis, IN, USA, 2015.

37. Rodrigues, F.; Antunes, F.; Matos, R. Safety plugins for risks prevention through design resourcing BIM. Constr. Innov. 2021, 21, 244-258. [CrossRef]

38. Hartmann, T.; van Meerveld, H.; Vossebeld, N.; Adriaanse, A. Aligning building information model tools and construction management methods. Autom. Constr. 2012, 22, 605-613. [CrossRef]

39. Zou, Y.; Kiviniemi, A.; Jones, S.W. A review of risk management through BIM and BIM-related technologies. Saf. Sci. 2017, 97, 88-98. [CrossRef]

40. Jin, R.; Zhong, B.; Ma, L.; Hashemi, A.; Ding, L. Integrating BIM with building performance analysis in project life-cycle. Autom. Constr. 2019, 106, 102861. [CrossRef]

41. Bloch, T.; Sacks, R. Clustering Information Types for Semantic Enrichment of Building Information Models to Support Automated Code Compliance Checking. J. Comput. Civ. Eng. 2020, 34, 4020040. [CrossRef]

42. Rodrigues, F.; Estrada, J.; Antunes, F.; Swuste, P. Safety through Design: A BIM-Based Framework; Springer: Singapore, 2018; pp. 112-123.

43. Hallowell, M.R.; Hansen, D. Measuring and improving designer hazard recognition skill: Critical competency to enable prevention through design. Saf. Sci. 2016, 82, 254-263. [CrossRef]

44. Abbasi, S.; Taghizade, K.; Noorzai, E. BIM-Based Combination of Takt Time and Discrete Event Simulation for Implementing Just in Time in Construction Scheduling under Constraints. J. Constr. Eng. Manag. 2020, 146, 4020143. [CrossRef]

45. Sacks, R.; Dave, B.; Koskela, L.; Owen, R. Analysis framework for the interaction between lean construction and Building Information Modelling. In Proceedings of the 17th Annual Conference of the International Group for Lean Construction IGLC 17, Taipei, Taiwan, 15-17 July 2009; pp. 221-234.

46. Sheikhkhoshkar, M.; Pour Rahimian, F.; Kaveh, M.H.; Hosseini, M.R.; Edwards, D.J. Automated planning of concrete joint layouts with 4D-BIM. Autom. Constr. 2019, 107, 102943. [CrossRef]

47. Golizadeh, H.; Hon, C.K.; Drogemuller, R.; Hosseini, M.R. Digital engineering potential in addressing causes of construction accidents. Autom. Constr. 2018, 95, 284-295. [CrossRef] 